\title{
Effects of a Health Promotion Program on Elementary Students' Physical and Mental Health
}

\author{
Insook Lee1, Kyung-Sook Bang1* ${ }^{*}$, Sungjae Kim¹, Heeseung Choi' ${ }^{1}$, Inju Hwang² \\ ${ }^{1}$ College of Nursing, The Research Institute of Nursing Science, Seoul National University, Seoul, Korea \\ ${ }^{2}$ College of Nursing, Seoul National University, Seoul, Korea \\ Email: ${ }^{*}$ ksbang@snu.ac.kr
}

Received 19 July 2015; accepted 22 September 2015; published 25 September 2015

Copyright (C) 2015 by authors and Scientific Research Publishing Inc.

This work is licensed under the Creative Commons Attribution International License (CC BY). http://creativecommons.org/licenses/by/4.0/

(c) (i) Open Access

\begin{abstract}
Many health promotion programs have been implemented to prevent obesity and mental health problems among school-aged children. However, only a few programs included both physical and psychological measures to assess the effects of the program. The present study was designed to test the effects of a 6-week health promotion program on physical and mental health among school-aged children using physiological and psychological measures. A total of 74 elementary school students $\left(4^{\text {th }}\right.$ and $5^{\text {th }}$ grade) recruited from urban $(n=51)$ and rural areas $(n=23)$ participated in the study. We used the Korean version of the Kovacs' Children's Depression Inventory and the Conners-Wells' Adolescent Self-Report Scale-Short Form (CASS-S) to measure levels of depression and hyperactivity, respectively. To assess children's physical health, we measured body mass index (BMI), body fat percentage, and heart rate variability. In addition, children's healthrelated behaviors (e.g., eating and exercise habits) were assessed using the health promotion behavior scale. A total of 63 students (13 in the experimental and 50 in the control group) who completed both physiological and psychological measures were included in the final analysis. Compared to children in the control group, children in the experimental group showed a significant decrease in their level of hyperactivity $(t=-2.01, p=0.049)$ and increase in heart rate variability $(\mathrm{t}=\mathbf{- 2 . 3 5}, p=0.022$ ). No significant group differences were noted for depression, BMI, body fat percentage, and health promotion behaviors between the two groups. Findings of this study provided preliminary evidence of the effectiveness of a 6-week school-based health promotion program for improving emotional health among school-aged children living in a rural area. Future studies testing the effects of health promotion programs with longer sessions and programs focusing on social-emotional skill development are needed.
\end{abstract}

\footnotetext{
*Corresponding author.
} 


\section{Keywords}

\section{Health Promotion, Heart Rate Variability, Mental Health, School-Aged Children}

\section{Introduction}

In Korea, the physical and mental health of elementary students is of concern. Approximately $10 \%-20 \%$ of school-aged children in Korea have been categorized as overweight, and $5 \%-20 \%$ as obese [1]. In addition, physical activity and fitness have decreased and the mean height and weight for children and adolescents have increased over the past 10 years [2]. Based on a recent report on the mental health of Korean children and adolescents, 20 percent had suicidal ideation and 3 percent had attempted suicide during the past year, and one third of middle and high school students had experienced depressed mood [3]. Recently, the prevalence rate of ADHD symptoms among $4^{\text {th }}-6^{\text {th }}$ grade elementary students was reported to be up to $22.3 \%$ [4], and the high level of bullying and violence among elementary school students warned of the risk for mental health problems [5] [6]. Hence, the development of school-based health promotion programs and related policies is needed.

Many intervention programs have been implemented to promote physical and mental health among children and adolescents and have shown promising results in individual studies. The intervention, "Maum Meditation program" had positive effects on the promotion of self-esteem and school adjustment of children in the early grades of primary school in Korea [7]. However, a meta-analysis on the effects of school-based and after-school intervention programs on the BMIs of children and adolescents reported a low magnitude of effect size of 0.068 [8]. Thus, more efficient and sustainable health promotion programs and policies are required. In a meta-analysis on the effect of school-based anti-bullying programs, a small to moderate effect was found for victimization, suggesting that effective school-based anti-bullying programs should include training in emotional control, peer counseling, and the establishment of a school policy on bullying [6].

To date, most intervention programs have relied on self-report data and very few studies have included both psychological and physical measures to assess the effects of intervention programs. Even studies that have used objective measures for identifying the effect of school based health promotion programs in Korea used only weight change or BMI [9]-[11]. Recently, heart rate variability (HRV) has been used as an indicator for emotional stability as well as a valuable tool for assessing heart health. HRV is a non-invasive quantitative marker of cardiac autonomic function derived from continuous electrocardiogram (ECG) recordings [12]. Little change in HRV means a stable autonomic nerve system (i.e., stable emotional state). Even though HRV has been increasingly used as a stress marker, less research is available examining HRV in children, especially in Korea.

To address the gaps in current knowledge, this study aimed to examine the effect of a school-based health promotion program on both physical and mental health among late school-aged children. Changes in health status were assessed using both self-report measures and physiological measures, including HRV. Also, based on previous evidence of a positive effect of nature on physical and mental health [13] [14], we included naturerelated activities for the experimental group, and tested the effect of this program.

\section{Methods}

\subsection{Study Design}

This study used a quasi-experimental, non-equivalent pretest-post design to test the effect of a 6-week schoolbased health promotion program on school-aged children's health.

\subsection{Description of the Program}

Based on the Information-Motivation-Behavior (IMB) model [15], we developed the "Physical \& Mental Health" program to improve physical and mental health (i.e., body fat, HRV, depression, and hyperactivity) among school-aged children. The contents of the program were developed based on an extensive review of the literature and other health promotion programs for children. We provided information about various health topics and motivated participants to engage in health promotion activities and self-monitoring. "Physical \& Mental Health" consisted of three physical health promotion sessions and three mental health promotion sessions. The physical 
health sessions focused on the improvement of lifestyle habits including eating habits, exercise habits, and sleeping habits. The mental health promotion sessions addressed self-reflection and understanding others' perspectives, communication skills, and regulation of emotion (Table 1).

\subsection{Study Procedure and Participants}

\subsubsection{Procedure}

After obtaining approval from the principals and school health teachers of the two elementary schools, we recruited prospective participants. The two elementary schools were selected as a convenience, and assigned to either the experimental or the control group. A total of 74 elementary school students ( $4^{\text {th }}$ and $5^{\text {th }}$ grade) participated in the study; the total number of $4^{\text {th }}$ and $5^{\text {th }}$ grade in one school who agreed to participate were 23, and assigned to the experimental group, and the number of 1 class for each $4^{\text {th }}$ and $5^{\text {th }}$ grade who agreed to participate

Table 1. Main contents of the "Physical \& Mental Health" program for the experimental group.

\begin{tabular}{|c|c|c|c|c|c|}
\hline \multirow{2}{*}{ Theme } & \multirow{2}{*}{ Session } & \multirow{2}{*}{ Topic } & \multicolumn{3}{|c|}{ Main content } \\
\hline & & & Goal & Activities & Evaluation \\
\hline \multirow{3}{*}{$\begin{array}{l}\text { Physical } \\
\text { health }\end{array}$} & Session 1 & Eating habits & $\begin{array}{l}\text { Practicing healthy eating } \\
\text { habits }\end{array}$ & $\begin{array}{l}\cdot \text { Recording present eating } \\
\text { habits } \\
\text { - Learning about the } \\
\text { harmfulness of an } \\
\text { imbalanced diet, overeating, } \\
\text { and skipping meals } \\
\cdot \text { Planning healthy eating } \\
\text { habits }\end{array}$ & $\begin{array}{l}\text { - Recording everyday eating } \\
\text { habits in the workbook } \\
\text { - Making healthy food with } \\
\text { parents at home }\end{array}$ \\
\hline & Session 2 & Exercise habits & $\begin{array}{l}\text { - Practicing healthy exercise } \\
\text { habits }\end{array}$ & $\begin{array}{l}\text { - Recording my present } \\
\text { exercise habits } \\
\text { - Learning about the benefits } \\
\text { of exercise and how to } \\
\text { exercise in everyday life } \\
\text {-Planning exercise to } \\
\text { maintain an appropriate } \\
\text { weight }\end{array}$ & $\begin{array}{l}\text { - Recording everyday } \\
\text { exercise habits in the } \\
\text { workbook } \\
\text { - Exercising with friends and } \\
\text { family }\end{array}$ \\
\hline & Session 3 & Sleep habits & $\begin{array}{l}\text { Practicing healthy sleep } \\
\text { habits }\end{array}$ & $\begin{array}{l}\text { - Recording present sleeping } \\
\text { habits } \\
\text { - Learning about the } \\
\text { function of sleep and the } \\
\text { benefits of sound sleep } \\
\text {-Planning feasible sleeping } \\
\text { habits }\end{array}$ & $\begin{array}{l}\cdot \text { Recording everyday sleep } \\
\text { habits in the workbook } \\
\text {-Waking up early and } \\
\text { having time before going to } \\
\text { school }\end{array}$ \\
\hline \multirow{3}{*}{$\begin{array}{l}\text { Mental } \\
\text { health }\end{array}$} & Session 4 & $\begin{array}{l}\text { Understanding } \\
\text { the mind }\end{array}$ & $\begin{array}{l}\text { - Recognizing thoughts and } \\
\text { feelings on diverse } \\
\text { situations } \\
\text { - Understanding the other } \\
\text { person's situation and } \\
\text { perspective and shifting } \\
\text { one's own perspective }\end{array}$ & $\begin{array}{l}\text {-Sharing thoughts and } \\
\text { feelings about diverse } \\
\text { situations } \\
\text { - Shifting one's perspective } \\
\text { and learning about different } \\
\text { perspectives } \\
\text { - Becoming the tree on } \\
\text { gathered together }\end{array}$ & $\begin{array}{l}\text { - Talking about thoughts and } \\
\text { feelings while looking at } \\
\text { paintings and pictures of } \\
\text { diverse situations in the } \\
\text { workbook (over } 2 \text { minutes) } \\
\text {-Sharing thoughts and } \\
\text { feelings with parents }\end{array}$ \\
\hline & Session 5 & Communication & $\begin{array}{l}\text { - Understanding the concept } \\
\text { of communication } \\
\cdot \text { Knowing your own } \\
\text { communication style } \\
\text { - Learning how to } \\
\text { communicate effectively }\end{array}$ & $\begin{array}{l}\text {-Play games to learn about } \\
\text { communication } \\
\text {-Communicating while } \\
\text { changing headbands }\end{array}$ & $\begin{array}{l}\cdot \text { The most used words } \\
\cdot 5 \text { words from friends that } \\
\text { made you feel better } \\
\cdot 5 \text { words from friends that } \\
\text { made you feel worse }\end{array}$ \\
\hline & Session 6 & $\begin{array}{l}\text { Controlling } \\
\text { the mind }\end{array}$ & $\begin{array}{l}\text { - Understanding how to } \\
\text { control stress effectively } \\
\cdot \text { Understanding how to } \\
\text { control conflict and anger }\end{array}$ & $\begin{array}{l}\cdot \text { Making the leaf of feeling } \\
\cdot \text { Tearing the leaf of feeling } \\
\text { - Accepting diverse feelings } \\
\text { - Anger control training }\end{array}$ & $\begin{array}{l}\cdot \text { Practicing relaxation } \\
\text { - Reporting the experience } \\
\text { of anger control }\end{array}$ \\
\hline
\end{tabular}


were 51 in the other school, and assigned to the control group. The study was conducted from August to December 2013. For the experimental group, we provided intervention sessions every Friday for 6 weeks. Each intervention session took place for 45 minutes after school. No intervention was applied to the control group. The post test was carried out in December 2013. Participants in the experimental group were assessed before and after receiving the 6-week health promotion program. At the same interval, individuals in the control group were also assessed. Data were collected by the author and the research assistants who were well-trained and thoroughly understood the study. It took about 30 minutes for participants to fill out the self-questionnaire and complete the physiology procedure.

\subsubsection{Self-Report Measures}

1) Depression

Depression was measured using the Kovacs' Children's Depression Inventory (CDI) [16], which was translated into Korean [17]. This self-report inventory is composed of five subcategories: depressed mood (5 questions), behavior disorder (7 questions), loss of interest (7 questions), self-degradation (4 questions), and physiological symptoms (4 questions). It is assessed on a 3-point scale $(0,1$, and 2). Total scores range from 0 to 54 points and the higher the CDI total score, the more severe the depression is. The internal consistency reliability in this study, measured with Cronbach's $\alpha$, was 0.868 .

2) Hyperactivity

The Conners-Wells' Adolescent Self-Report Scale: Short Form (CASS: S) translated into Korean [18] was used to measure the level of hyperactivity. The scale is composed of 27 items and is rated on a 4-point scale (0, 1,2 , and 3). A higher score means a higher level of hyperactivity. The data collected using this inventory had a Cronbach's $\alpha$ of 0.880 .

3) Health promotion behavior

Health promotion behavior was measured using the questionnaire originally developed by Walker, Sechrist, and Pender [19] and then revised and supplemented in Korea [20] [21]. The questionnaire is composed of 36 questions: 11 items on eating habits, 8 items on exercise habits, 7 items on healthy living conditions, 5 items on personal relations, and 5 items on self-realization. The internal consistency reliability in this study (Cronbach's a) was 0.909 .

\subsubsection{Physiological Measures}

1) Body Mass Index (BMI) and body fat percentage

Body weight, height, and body fat percentage were measured with the J10 (Biospace, Seoul, Korea), a body composition analyzer. Juvenile body mass index was calculated by dividing the child's body weight (kg) by the square of the child's height $\left(\mathrm{m}^{2}\right)$. We measured the participant's body fat percentage, which is an indicator of the ratio of body fat to body weight.

2) Heart Rate Variability (HRV)

Autonomic nervous system function was assessed using Heart Rate Variability (HRV) analysis. Participants in the experimental group were assessed before and after receiving the 6-week health promotion program. HRV was measured with PolyG-I (Laxtha, Daejeon, Korea) in a quiet room. During the test, we let participants lie quietly and attached 2 electrodes on their wrists for 3 minutes. Participants were instructed to close their eyes but not to fall asleep. If the participants moved and an abnormal wave was shown, we stopped the test and re-measured.

\subsection{Ethical Considerations}

This study was approved by the S University Institutional Review Board (Approval No.: 2013-64). Written Informed consent was obtained from all participants and their parents. Parental consent and child assent were obtained before students completed the pretest. Children who participated in this study were assured of anonymity and confidentiality.

\subsection{Data Analysis}

SPSS 21.0 for Windows was used for analysis. To test homogeneity between the two groups, a t-test and chisquare test were applied. To confirm the effect of the intervention, the pretest-posttest difference was calculated 
and compared between the two groups using a t-test. The normality of the physiological variables was confirmed using the Kolmogorov-Smirnov test. Two-tailed $p$-values $<0.05$ were considered significant.

\section{Results}

\subsection{Participants' Demographic Characteristics and Homogeneity Test Results}

The participants' demographic and biological characteristics assessed at baseline are shown in Table 2 and Table 3. Homogeneity tests were also performed on the dependent variables between the experimental and control groups at the time of the pretest. No significant differences were reported in demographic characteristics and dependent variables between the two groups at baseline.

Among the 84 participants, only 13 of 23 children in the experimental group completed the physiological measures for both the pre- and posttest, whereas all 50 participants in the control group completed the physiological measures both times. Therefore, we included only 63 students (13 in the experimental and 50 in the control group) in further analysis.

\subsection{Effects of Health Promotion Program on Dependent Variables}

Findings for analyses of the overall program effects on physical and mental health outcomes by self-report questionnaire are shown in Table 4. For mental health, no significant difference was shown between two groups. Only changes in the level of hyperactivity were significantly different between the experimental and control groups $(\mathrm{t}=-2.01, p=0.049)$. Also, health promotion behavior was not different between two groups.

In biological index, children in the experimental group showed significant changes in $\operatorname{LF}(\mathrm{t}=-2.35, p=0.022)$ and HF of HRV ( $\mathrm{t}=2.35, p=0.022)$ after the intervention compared to the control group. This meant that the experimental group's parasympathetic nerve was more activated than that of the control group after the intervention. No significant group differences were noted in BMI and body fat percentage (Table 5).

Table 2. Homogeneity tests of general characteristics and self-report questionnaire between the two groups at the pretest.

\begin{tabular}{|c|c|c|c|c|c|}
\hline Variable & Categories & $\begin{array}{c}\text { Experimental } \\
(n=23) \\
n(\%) \text { or Mean } \pm \text { SD }\end{array}$ & $\begin{array}{c}\text { Control } \\
(\mathrm{n}=51) \\
\mathrm{n}(\%) \text { or Mean } \pm \mathrm{SD}\end{array}$ & $\begin{array}{l}\chi^{2} \\
\text { or } \mathrm{t}\end{array}$ & $p$ \\
\hline \multirow{2}{*}{ Gender } & Boy & $11(47.8)$ & $25(49.0)$ & 0.01 & 0.924 \\
\hline & Girl & $12(52.2)$ & $26(51.0)$ & & \\
\hline \multirow{2}{*}{ Grade } & 4th grade & $12(52.2)$ & 27 (52.9) & 0.00 & 0.951 \\
\hline & 5th grade & $11(47.8)$ & $24(47.1)$ & & \\
\hline \multirow{3}{*}{$\begin{array}{c}\text { Perceived } \\
\text { health status }\end{array}$} & Healthy & $16(69.6)$ & $45(88.2)$ & & \\
\hline & Moderate & $7(30.4)$ & $5(9.8)$ & $5.28^{*}$ & 0.071 \\
\hline & Unhealthy & $0(0)$ & $1(2.0)$ & & \\
\hline \multirow{3}{*}{$\begin{array}{l}\text { Perceived body } \\
\text { shape }\end{array}$} & Thin & $9(39.1)$ & $11(21.6)$ & & \\
\hline & Moderate & $6(26.1)$ & $22(43.1)$ & 3.03 & 0.220 \\
\hline & Fat & $8(34.8)$ & $18(35.3)$ & & \\
\hline \multirow{3}{*}{$\begin{array}{l}\text { Economic } \\
\text { status }\end{array}$} & High & $11(47.8)$ & $30(58.8)$ & & \\
\hline & Middle & $11(47.8)$ & 19 (37.3) & $0.79^{*}$ & 0.674 \\
\hline & Low & $1(4.4)$ & $2(3.9)$ & & \\
\hline \multicolumn{2}{|c|}{ Walking time/day (minutes) } & $55.43 \pm 51.05$ & $69.58 \pm 49.17$ & -1.13 & 0.260 \\
\hline \multirow{3}{*}{$\begin{array}{c}\text { Self-report } \\
\text { questionnaire }\end{array}$} & Depression & $7.78 \pm 4.66$ & $7.12 \pm 6.46$ & 0.44 & 0.65 \\
\hline & ADHD & $13.44 \pm 8.31$ & $11.82 \pm 8.32$ & 0.77 & 0.443 \\
\hline & Health promotion behavior & $109.70 \pm 13.68$ & $112.25 \pm 15.88$ & -0.71 & 0.480 \\
\hline
\end{tabular}

*Fisher's exact test. 
Table 3. Homogeneity tests of biological characteristics between the two groups at the pretest.

\begin{tabular}{|c|c|c|c|c|c|}
\hline & \multirow{2}{*}{ Variables } & $\begin{array}{l}\text { Experimental } \\
\quad(\mathrm{n}=13)\end{array}$ & $\begin{array}{l}\text { Control } \\
(\mathrm{n}=50)\end{array}$ & \multirow[t]{2}{*}{$\mathrm{t}$} & \multirow[t]{2}{*}{$p$} \\
\hline & & Mean \pm SD & Mean \pm SD & & \\
\hline BMI & & $19.45 \pm 4.97$ & $19.08 \pm 2.85$ & 0.255 & 0.802 \\
\hline Body fat & & $26.40 \pm 13.49$ & $25.03 \pm 7.79$ & 0.353 & 0.729 \\
\hline \multirow{3}{*}{$\begin{array}{l}\text { Heart rate } \\
\text { variability }\end{array}$} & $\mathrm{LF} / \mathrm{HF}$ & $1.38 \pm 0.87$ & $1.24 \pm 1.18$ & 0.410 & 0.683 \\
\hline & LF (sympathetic nerve activation) & $0.53 \pm 0.15$ & $0.47 \pm 0.18$ & 1.132 & 0.262 \\
\hline & HF (Parasympathetic nerve activation) & $0.47 \pm 0.15$ & $0.53 \pm 0.18$ & -1.132 & 0.262 \\
\hline
\end{tabular}

LF = Low Frequency, HF = High Frequency, BMI = Body Mass Index.

Table 4. Comparisons of differences between the pre- and posttest (posttest-pretest) for the two groups on the self-report questionnaire.

\begin{tabular}{cccccc}
\hline & $\begin{array}{c}\text { Experimental } \\
(\mathrm{n}=23)\end{array}$ & $\begin{array}{c}\text { Control } \\
(\mathrm{n}=51)\end{array}$ & $\mathrm{t}$ & $p$ \\
\cline { 2 - 4 } Variable & Mean \pm SD & Mean \pm SD & & 0.142 \\
Depression & $-1.52 \pm 2.87$ & $-0.37 \pm 3.03$ & -1.49 & -0.049 \\
Hyperactivity & $-3.96 \pm 5.66$ & $-0.86 \pm 6.31$ & -2.01 & 0.961 \\
\hline Health promotion behaviors & $0.59 \pm 10.87$ & $0.73 \pm 10.95$ & -0.05 & \\
\hline
\end{tabular}

Table 5. Comparisons of differences between the pre- and posttest (posttest-pretest) for the two groups on the biological index.

\begin{tabular}{|c|c|c|c|c|c|}
\hline & \multirow[t]{2}{*}{ Variable } & $\begin{array}{l}\text { Experimental } \\
\quad(\mathrm{n}=13)\end{array}$ & $\begin{array}{l}\text { Control } \\
(\mathrm{n}=50)\end{array}$ & \multirow[t]{2}{*}{$\mathrm{t}$} & \multirow[t]{2}{*}{$p$} \\
\hline & & Mean \pm SD & Mean \pm SD & & \\
\hline & BMI & $0.45 \pm 0.54$ & $-0.28 \pm 3.50$ & 0.74 & 0.461 \\
\hline & Body fat & $1.58 \pm 8.53$ & $-0.75 \pm 1.55$ & 0.98 & 0.345 \\
\hline \multirow{3}{*}{ HRV } & $\mathrm{LF} / \mathrm{HF}$ & $-0.63 \pm 0.96$ & $-0.01 \pm 1.03$ & -1.94 & 0.057 \\
\hline & LF (sympathetic nerve activation) & $-0.12 \pm 0.17$ & $0.00 \pm 0.18$ & -2.35 & 0.022 \\
\hline & HF (Parasympathetic nerve activation) & $0.12 \pm 0.17$ & $0.00 \pm 0.18$ & 2.35 & 0.022 \\
\hline
\end{tabular}

BMI = Body Mass Index, HRV = Heart rate variability, LF = Low Frequency, HF = High Frequency.

\section{Discussion}

This study was conducted to assess the effects of a 6-week school-based health promotion program for late school-aged children. The results of this study showed a significant decrease in the level of hyperactivity and increase in relaxation expressed by parasympathetic activation.

In terms of HRV, vital variability reflects the heart's ability to respond to physiological and environmental stimuli. Because of the specific autonomic nervous innervations of the heart, HRV is recognized as a quantitative marker of the autonomic nervous system: it is influenced by sympathetic activity (SA) and vagal parasympathetic activity (PA). For children, studies measuring HRV have not been frequently reported. One study reported short-term HRV in a population-based sample of 10-year-old children [12], and low HRV (i.e., low PA, HF) has previously been linked to poor emotion regulation, high stress, decreased stress reactivity, and increased stress vulnerability, also in children [22] [23].

In this study, the experimental group showed more decrease in LF compared to the control group. This implied that the intervention was effective in decreasing children's stress (e.g., resulting from peer problems) and negative emotions such as anger and anxiety. A previous study also showed a positive correlation between anxi- 
ety and higher LF and the stress marker cortisol [24]. This meant that high stress among children was associated with higher LF/HF, which may reflect more sympathetic activation over parasympathetic activation. This might explain why overweight/obese children demonstrated lower HF compared to normal weight children in previous a study [25].

Even though we could not find a relationship between depression and LF/HF scores, this health promotion program might help improve emotional stability among elementary school students. Other evidence in support of this proposition is the greater decrement in hyperactivity scores seen in the experimental group compared to that of the control group.

However, this health promotion program showed no significant effect on BMI or body fat proportion. It may be possible that two to three months was not enough time to elicit a change in weight. One study reported positive effects of a 12-week24-session after-school health promotion program for Hispanic elementary school children on BMI and eating habits [26], and using jazz in school program showed improving physical strength and self- efficacy of the Korean elementary school students [27]. In this study, interventions consisted of health education and indoor activity. We encouraged regular outdoor activities, but did not include outdoor physical activity in the intervention program. In addition, we focused more on emotional health, emphasizing peer relationships and communication. This may explain why we found more obvious changes in emotional outcomes than physical outcomes. In addition, this program was applied mostly to normal weight student, not obese children. Still, we observed greater reductions in BMI in the experimental group than the control group, but the sample size for the experimental group was too small to show a significant effect.

This study has several limitations. First, the regions for the experimental and control group were selected as a convenience, and not comparable: the region for the experimental group was a rural area whereas the region for the control group was a capital city. However, the general characteristics between the two groups at baseline were homogeneous. Secondly, only 13 among 23 children in the experimental group participated in the post test. The high attrition rate in the experimental group could have affected the results. Also, because we did not measure directly the effect of education on diet and sleep, we could not conclude that this program had effects on compliance with good eating and sleeping habits.

Although this study had some limitations, it is meaningful in assessing the possibility of emotional health promotion using school-based health programs. Additional research with a more sufficient sample size is suggested.

\section{Conclusion}

The findings of this study provided preliminary evidence of the effectiveness of a 6-week school-based health promotion program for improving emotional health among school-aged children living in a rural region. Future research should examine whether the effectiveness of physical and mental health promotion programs can be enhanced through refinements such as more focused attention to social-emotional skill development.

\section{Acknowledgements}

This work was supported by a Research Grant of the Korea Forest Service.

\section{Conflict of Interest}

No potential conflict of interest relevant to this article was reported.

\section{References}

[1] Ahn, Y., Choi, S. and Sohn, M. (2013) Adiposity of Korean School-Age Children Measured by National and International Growth Charts. Research in Nursing and Health, 36, 16-25. http://dx.doi.org/10.1002/nur.21510

[2] Heo, J. (2009) An Examination of the Relationships among Body Shape, Physical Fitness and Body Composition in Elementary School Students. The Korean Journal of Growth and Development, 17, 201-209.

[3] Mo, S.H., Kim, H.J., Lee, S.Y., Kim, J.H. and Yoon, K.M. (2013) Study on the Policy for Mental Health Promotion of Children and Adolescents III: Combined Report. National Youth Policy Institute, Seoul, 1-338.

[4] Song, Y.J. (2014) Estimated Prevalence of ADHD Symptoms and Relationships among ADHD Symptoms, Environmental Variables, and Peer Relationships in Elementary School Students. Asian Journal of Education, 15, 189-217. 
[5] Kim, D., Park, A. and Lee, K. (2008) Effect of PC Game to Improve Interpersonal Abilities for Prevention of Bullying and Violence in Elementary School Environment. Asian Journal of Education, 9, 49-65. http://dx.doi.org/10.15753/aje.2008.9.2.003

[6] Lee, S., Kim, C.J. and Kim, D.H. (2013) A Meta-Analysis of the Effect of School-Based Anti-Bullying Programs. Journal of Child Health Care: For Professionals Working with Children in the Hospital and Community, 3 October.

[7] Yoo, Y.G. and Lee, I.S. (2013) The Effects of School-Based Maum Meditation Program on the Self-Esteem and School Adjustment in Primary School Students. Global Journal of Health Science, 5, 14-27.

[8] Vasques, C., Magalhaes, P., Cortinhas, A., Mota, P., Leitao, J. and Lopes, V.P. (2014) Effects of Intervention Programs on Child and Adolescent BMI: A Meta-Analysis Study. Journal of Physical Activity and Health, 11, 426-444. http://dx.doi.org/10.1123/jpah.2012-0035

[9] Lee, K.Y., Nam, H.M. and Lee, J.R. (2007) Effect of Elementary School Based Intervention to Prevent Obesity in Children. Journal of Korean Society for the Study of Obesity, 16, 125-129.

[10] Hong, Y.H., Park, J.K. and Lee, D.H. (2010) The Evaluation of Obese Control Program in Elementary School. Journal of the Korean Society for the Study of Obesity, 19, 9-15.

[11] Nam, S.M. (2013) Effects of Club Obesity Management Program for Obese Children on Body Composition, SelfEfficacy, and Health Promotion. Journal of Korean Public Health Nursing, 27, 619-632. http://dx.doi.org/10.5932/JKPHN.2013.27.3.619

[12] Jarrin, D.C., McGrath, J.J., Poirier, P., Séguin, L., Tremblay, R.E., Montplaisir, J.Y., et al. (2015) Short-Term Heart Rate Variability in a Population-Based Sample of 10-Year-Old Children. Pediatric Cardiology, 36, 41-48.

[13] Kim, D.J. and Lee, S.J. (2014) Effects of Forest Therapy Program in School Forest on Employment Stress and Anxiety of University Students. Journal of the Korean Society for Plants, People and Environment, 17, 107-115. http://dx.doi.org/10.11628/ksppe.2014.17.2.107

[14] Park, H.J., Jung, Y.O. and Kim, J.P. (2014) The Effect of the Eco-Experience Learning on the Fostering of Elementary School Students' Sociality. Journal of the Korean Society for Plants, People and Environment, 13, 101-108.

[15] Fisher, W.A., Kohut, T., Schachner, H. and Stenger, P. (2011) Understanding Self-Monitoring of Blood Glucose among Individuals with Type 1 and Type 2 Diabetes. An Information-Motivation-Behavioral Skills Analysis. The Diabetes Educator, 37, 85-94. http://dx.doi.org/10.1177/0145721710391479

[16] Kovacs, M. (1985) The Children’s Depression Inventory (CDI). Psychopharmacology Bulletin, 21, 995-998.

[17] Cho, S.C. and Lee, Y.S. (1990) Development of the Korean Form of the Kovacs' Children’s Depression Inventory. Journal of Korean Neuropsychiatric Association, 29, 943-956.

[18] Bahn, G.H., Shin, M.S., Cho, S.C. and Hong, K.-E. (2001) A Preliminary Study for the Development of the Assessment Scale for ADHD in Adolescents: Reliability and Validity for CASS(S). Journal of Child \& Adolescent Psychiatry, 12, 218-224.

[19] Walker, S.N., Sechrist, K.R. and Pender, N.J. (1987) The Health-Promoting Lifestyle Profile: Development and Psychometric Characteristics. Nursing Research, 36, 76-81. http://dx.doi.org/10.1097/00006199-198703000-00002

[20] Kim, M.H. (2000) A Study on the Relations of Health Promoting Daily Life Style and Self-Efficiency about Boys' Obesity. Central University Social Education Development Institute, Seoul.

[21] Jung, S.H. (2006) The Effects of Weight Management Educational Program Based Problem-Based Learning (PBL) on Self-Efficacy, Health Promotion Behavior and Obesity Index in Obese Children. Korea University Graduate School of Education, Seoul.

[22] Porges, S.W. (1995) Cardiac Vagal Tone: A Physiological Index of Stress. Neuroscience and Biobehavioral Reviews, 19, 225-233. http://dx.doi.org/10.1016/0149-7634(94)00066-A

[23] Porges, S.W., Doussard-Roosevelt, J.A. and Maiti, A.K. (1994) Vagal Tone and the Physiological Regulation of Emotion. Monographs of the Society for Research in Child Development, 59, 167-186. http://dx.doi.org/10.2307/1166144

[24] Michels, N., Sioen, I., Clays, E., et al. (2013) Children’s Heart Rate Variability as Stress Indicator: Association with Reported Stress and Cortisol. Biological Psychology, 94, 433-440. http://dx.doi.org/10.1016/j.biopsycho.2013.08.005

[25] Birch, S.L., Duncan, M.J. and Franklin, C. (2012) Overweight and Reduced Heart Rate Variability in British Children: An Exploratory Study. Preventive Medicine, 55, 430-432. http://dx.doi.org/10.1016/j.ypmed.2012.09.015

[26] de Heer, H.D., Koehly, L., Pederson, R. and Morera, O. (2011) Effectiveness and Spillover of an After-School Health Promotion Program for Hispanic Elementary School Children. American Journal of Public Health, 101, 1907-1913. http://dx.doi.org/10.2105/ajph.2011.300177

[27] Nam, H.Y. and Lee, D.K. (2009) The Effects of Jazz Dance Program on the Physical Strength and Self-Efficacy of the Elementary School Students. The Korean Journal of the Elementary Physical Education, 15, 123-133. 